\title{
BMJ Open Does attendance of a prenatal education course reduce rates of caesarean section on maternal request? A questionnaire study in a tertiary women hospital in Shanghai, China
}

Yifei Gao, ${ }^{1}$ Yunhui Tang, ${ }^{1}$ Mancy Tong, ${ }^{2}$ Yan Du,,${ }^{1}$ Qi Chen ${ }^{01,3}$

To cite: Gao Y, Tang Y, Tong M, et al. Does attendance of a prenatal education course reduce rates of caesarean section on maternal request? A questionnaire study in a tertiary women hospital in Shanghai, China. BMJ Open 2019;9:e029437. doi:10.1136/ bmjopen-2019-029437

- Prepublication history for this paper is available online. To view these files please visit the journal online (http://dx.doi org/10.1136/bmjopen-2019029437).

YG and YT contributed equally.

Received 25 January 2019

Revised 25 March 2019

Accepted 4 June 2019

Check for updates

(C) Author(s) (or their employer(s)) 2019. Re-use permitted under CC BY-NC. No commercial re-use. See rights and permissions. Published by BMJ.

${ }^{1}$ The Hospital of Obstetrics \& Gynaecology, Fudan University, Shanghai, China

2Department of Obstetrics, Gynecology and Reproductive Sciences, Yale University, New Haven, UK

${ }^{3}$ Obstetrics \& Gynaecology, University of Auckland, Auckland, New Zealand

\section{Correspondence to}

Dr. Yan Du;

sophiedu_61@163.com and

Dr Qi Chen;

q.chen@auckland.ac.nz

\section{ABSTRACT}

Objective Caesarean section rates have significantly increased worldwide. China has a caesarean rate of $46 \%$, with a moderate contribution of caesarean section on maternal request. In this study, we investigated the association between maternal characteristics, attendance at a prenatal education course and caesarean section on maternal request.

Design Questionnaire study.

Setting Tertiary hospital in China.

Sample 564 questionnaires.

Methods On postpartum day 42, questionnaire data were collected. Data including age, parity, gravida, delivery mode, educational level, residence status, living condition and attendance of prenatal education course were analysed.

Primary and secondary outcome measures Factors associated with caesarean section on maternal request. Results $46 \%$ of women were delivered by caesarean section on maternal request. Maternal age and residence status were all significantly associated with having a caesarean section on maternal request. The $\mathrm{OR}$ of an increase in caesarean section on maternal request in women over 30 years was 2.42 (95\%confidence limits 1.597 to $3.666)$, compared with women under 30 years. $75 \%$ more women who resided in Shanghai had caesarean section on maternal request, compared with women who resided outside of Shanghai. However, there was a significant reduction (35\%) in the number of caesarean sections on maternal request in women who attended a prenatal education course $(p=0.029)$. There was no significant association between attendance of a prenatal education course and the other maternal characteristics studied. Conclusion Maternal age is associated with an increased risk of caesarean section on maternal request. For women of all age, attendance of a prenatal education course significantly reduced the rate of caesarean section on maternal request. Our data suggest that promotion of a prenatal education course is an important tool in China to reduce the rate of caesarean section.

\section{INTRODUCTION}

The rate of caesarean section has significantly increased worldwide over the last
Strengths and limitations of this study

- Prenatal education courses are not performed in most women's hospital in China.

- This survey study was done in the largest women's hospital in China with $>12000$ deliveries a year.

- We found that attendance of a prenatal education course could affect the rate of caesarean section on maternal request.

- Regional difference in China may also result in a bias.

three decades. ${ }^{1}$ Caesarean section in low-risk women can result in a small overall increase in poor outcomes and typically takes longer to recover from than vaginal birth. Caesarean section also increases the risk of infection and associated morbidity up to 20-folds in comparison to vaginal delivery. ${ }^{1}$ Therefore, the WHO recommends that caesarean section should be performed only when there is a medical indication (WHO Statement on Caesarean Section Rate, 2015). Today globally, approximate $2.5 \%-18 \%$ of caesarean sections are carried out without any medical indication, dependent on the regions. ${ }^{1-3}$

According to the WHO report, China has a higher caesarean section rate in comparison to other countries. Previous studies reported that the caesarean section rate has significantly increased to $35 \%-50 \%$ (regionally dependent) in China ${ }^{45}$ and the most recent caesarean section rate was $\sim 46 \%$ in China. ${ }^{1}$ The predominant reason for this trend may be an increase in the number of caesarean section on maternal request in the last decade. ${ }^{45}$ Worldwide, the estimated rate of caesarean section on maternal request was 10\%-20\% in Northern Europe, USA, Sweden and Australia. ${ }^{6-9}$ We previously reported in 2012 that the rate of caesarean section on 


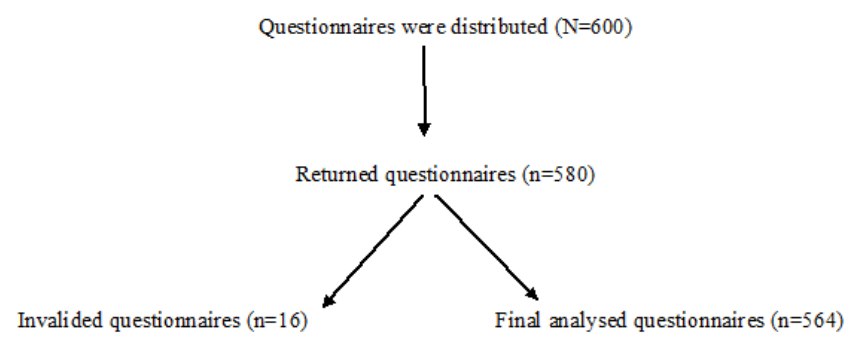

Figure 1 Flowchart of data collection.

maternal request was about $10 \% .{ }^{10}$ However, a recent study reported the rate of caesarean section on maternal request has significantly increased to $38 \%$ in China. ${ }^{4}$

Fear and anxiety of childbirth as well as psychological stress during labour and birth appear to be the most important reasons for caesarean section on maternal request. About $5 \%-40 \%$ of pregnant women fear childbirth in western countries, ${ }^{11}{ }^{12}$ and a recent study reported that Chinese pregnant women have moderate levels of childbirth fear and anxiety. ${ }^{13}$ In addition, failure of hospitals to support normal delivery including a supportive birthing environment can result in maternal stress and anxiety during labour and birth. ${ }^{14}$ A satisfying birth environment can minimise maternal stress and anxiety during labour and birth and support physiological birth. ${ }^{14}$ Finally, concerns about the safety of the baby have become another main reason for caesarean section on maternal request in a large proportion of pregnant women. ${ }^{15}$

Globally, factors associated with caesarean section on maternal request may vary. Educational levels of pregnant women, prenatal care system, economic condition, the patient-doctor relationship and performance of prenatal education course are different among countries and ethnicities. To date, studies investigating the association of maternal characteristics or social environment and caesarean section on maternal request are limited. In this retrospective study, we analysed the factors that are associated with caesarean section on maternal request in one of the largest tertiary women hospitals in China.

\section{METHODS}

This questionnaire study was performed in The Hospital of Obstetrics and Gynaecology of Fudan University, Shanghai, China from January 2017 to June 2017.

\section{Patient and public involvement}

There was no patient and public involvement in this study.

\section{Study design and participants}

A total of 600 pregnant women who delivered a live fetus at term in our hospital and returned for postpartum clinic on day 42 were asked at random to complete a voluntary questionnaire. All women surveyed had no maternal and fetal complications during pregnancy and delivery. The questionnaire included questions on basic maternal characteristics, postpartum care including diet, breast feeding and neonatal care. To reduce the recall bias, this study was carried out in 6 months. Five hundred and eighty questionnaires were returned, 16 invalid questionnaires were excluded as they were incompletion and overall 564 questionnaires were analysed in this study (figure 1). In this study, factors associated with caesarean section on maternal request were analysed. Basic maternal characteristics included maternal age, parity, gravida, delivery mode, maternal weight before pregnancy, educational level of mother, residence status (permanently reside in Shanghai or permanently reside outside of Shanghai), living conditions and attendance of a prenatal education course. Living condition was referred as economic level. Caesarean section on maternal request was defined as a planned elective caesarean section with no medical indication. No women who had an emergency caesarean section were included in our study.

The prenatal education course described in our study is a free half-day intensive one by one course for pregnant women between 36 and 37 weeks of gestation in our hospital. It is common that either husbands or parents (in particular pregnant women's mothers) come along with the pregnant women. The course is led and run by experienced and specialised midwives in our hospital. Course information focuses on supporting pregnant women to prepare for labour and normal births including the role of the father during labour and birth, labour coping skills and management of pain during labour and birth.

The Hospital of Obstetrics and Gynaecology of Fudan University is located in Shanghai, the wealthiest city in China and is a leading provider of tertiary maternity care. Many women who reside outside of Shanghai come to give birth in our hospital because of the services provided and the hospital has $>12000$ deliveries in a year.

\section{Power of sample size}

The sample size calculation was based on the estimated incidence of caesarean section $(40 \%)$ in China. ${ }^{1}$ At least 130 respondents were needed for a statistical power of $90 \%$ for each group to detect a significant difference between two groups at a level of 0.05 (two-tailed). We overenrolled to allow for attrition, setting our final recruitment target at 600 women.

\section{Statistical analysis}

The statistical difference in maternal age and maternal body weight before pregnancy between women with vaginal delivery and women with caesarean section was assessed with a Mann-Whitney U-test using the Prism software package. The statistical difference in parity, gravida, educational level, residence status, attendance of a prenatal education course between women with vaginal delivery and women with caesarean section was assessed with $\chi^{2}$ test (or Fisher's exact test) using the Prism software package. The analysis in the rate of caesarean section on maternal request was assessed by OR and $95 \%$ confidence limits (CL) using OpenEpi software. P values of $<0.05$ were considered significant. 
Table 1 General clinical parameters in study cohort according to the mode of delivery

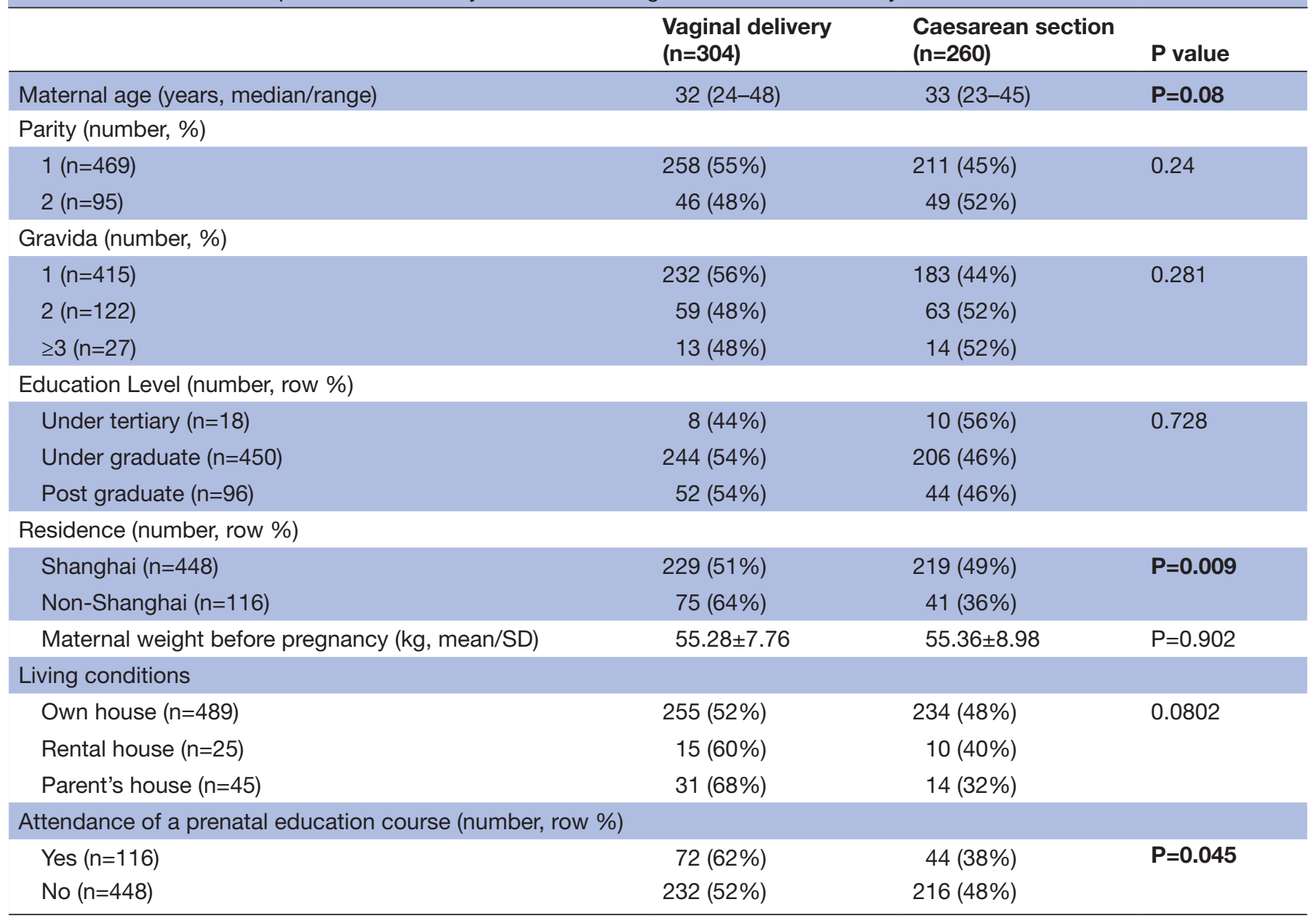

Bold values are statistically significant.

\section{RESULTS}

The median maternal age was 32 years (ranging from 23 to 48 years). Of 564 women, 469 (83\%) women were nulliparous and 304 (54\%) women had a vaginal delivery and $260(46 \%)$ women had a planned caesarean section on maternal request. The majority of women $(97 \%)$ had a tertiary or above education (a bachelor's degree or masters or $\mathrm{PhD}$ ) and $448(80 \%)$ women resided in Shanghai. Only $116(20.6 \%)$ women attended the prenatal education course before delivery.

The demographic information of women with vaginal delivery and with caesarean section are summarised in table 1. There was no statistical difference in parity, gravida, educational level and maternal weight before pregnancy between women with vaginal delivery and women with caesarean section (table 1). However, the maternal age in women with caesarean section was significantly higher compared with women with vaginal delivery $(\mathrm{p}=0.008$, table 1). In addition, women who resided in Shanghai had a significantly higher caesarean section rate than women who resided outside of Shanghai $(p=0.005$, table 1$)$. The OR of an increase in caesarean section on maternal request in women who resided in Shanghai was 1.749 (95\% CL 1.14 to
2.67, table 2), compared with women who resided outside of Shanghai. Women who attended the prenatal education course had a significantly lower rate of caesarean section on maternal request compared with women who did not attend to the prenatal education course $(p=0.045$, table 1$)$. The OR of a reduction in caesarean section on maternal request in women who attended to the prenatal education course was 0.656 (95\% CL 0.432 to 0.997 , table 2), compared with women who did not attend to the prenatal education course.

To analyse the association of caesarean section on maternal request and age distribution, we then divided women into three groups by age (table 3 ). We found that women between 30 and 39 years had the highest caesarean section rate $(78 \%)$ compared with women between 20 and 29 years $(15 \%)$ or women over 40 years $(6.5 \%)$.

We then analysed whether there was a difference in educational levels between women who resided in Shanghai and women who resided outside of Shanghai. There was no statistical difference in tertiary or above level education between the two groups (98\% vs $93 \%$ ).

We further analysed factors which affected pregnant women attending of a prenatal education course 


\begin{tabular}{|c|c|c|c|c|c|}
\hline & Caesarean section & Vaginal delivery & OR & $95 \% \mathrm{CL}$ & $P$ value \\
\hline \multicolumn{6}{|c|}{ Maternal age, years (number, \%) } \\
\hline $20-29(n=130)$ & $39(30)$ & $91(70)$ & 2.392 & 1.57 to 3.65 & $<0.0001$ \\
\hline $30-39(n=403)$ & $204(51)$ & $199(49)$ & & & \\
\hline \multicolumn{6}{|c|}{ Maternal age, years (number, \%) } \\
\hline $30-39(n=403)$ & $204(51)$ & $199(49)$ & 0.844 & 0.41 to 1.75 & 0.395 \\
\hline$\geq 40(n=31)$ & $17(55)$ & $14(45)$ & & & \\
\hline \multicolumn{6}{|c|}{ Maternal age, years (number, \%) } \\
\hline $20-29(n=130)$ & $39(30)$ & $91(70)$ & 2.833 & 1.27 to 6.31 & 0.009 \\
\hline$\geq 40(n=31)$ & $17(55)$ & $14(45)$ & & & \\
\hline \multicolumn{6}{|c|}{ Residence status (number, \%) } \\
\hline Shanghai $(n=448)$ & $219(84)$ & $229(75)$ & 1.749 & 1.14 to 2.67 & 0.005 \\
\hline Non-Shanghai $(n=116)$ & $41(16)$ & $75(25)$ & & & \\
\hline \multicolumn{6}{|c|}{ Attendance of a prenatal education course (number, \%) } \\
\hline Yes $(n=116)$ & $44(38)$ & $72(62)$ & 0.656 & 0.43 to 0.99 & 0.029 \\
\hline No $(n=448)$ & $216(48)$ & $232(52)$ & & & \\
\hline
\end{tabular}

(table 4). There was no statistical difference in maternal age, educational level, residence status, parity and gravida between women who attended to the prenatal education course and women who did not.

\section{DISCUSSION}

\section{Main findings}

In this questionnaire study with a medium sample size, we found that maternal age, residence status and attendance of a prenatal education course could affect the rate of caesarean section on maternal request. In contrast, parity, gravida and maternal education level were not associated with an increased rate of caesarean section on maternal request. In addition, there were significant association between attendance of a prenatal education course and the other maternal characteristics studied.

\section{Strengths and limitations}

The effect of attendance of a prenatal education course on the rate of caesarean section on maternal request has not been fully investigated. In addition, prenatal education courses have not been fully set up in most maternity hospitals in China. The Hospital of Obstetrics and Gynaecology of Fudan University is one of the largest and top ranked tertiary maternity hospitals with $>12000$ deliveries a year in China. Our hospital does provide a one-on-one prenatal education course.

There were some limitations in this study. First, our questionnaire study was done in a single tertiary women hospital with a relative medium sample size $(n=564)$, but this was relatively small compared with the 12000 deliveries in the hospital every year. Our hospital's maternity care package may be different to other hospitals in China and these regional differences may result in a bias. Therefore, our findings need to be further investigated with a large multicentre trial. Second, our prenatal education course was not designed to reduce the rates of obstetric intervention. This limitation must be taken into account when considering the association between prenatal education courses and perinatal outcomes. Third, due to the nature of the questionnaire study, all the data used in our study were self-reported. A possible recall bias should also be taken into account.

\section{Interpretation}

Compared to 2003, worldwide caesarean section rates have doubled by 2018. There are varied reasons for this increasing trend, but we believe that the increased rate

Table 3 The association of age distribution and rate of caesarean section on maternal request

\begin{tabular}{lcc}
\hline Age distribution & Women with caesarean section (n=260) & P value \\
\hline 20-29years (number, \%) (lower CL, upper CL) & $39(15 \%)(10.89 \%$ to 19.93\%) & $P<0.001$ \\
30-39years (number, \%) (lower CL to upper CL) & $204(78.5 \%)(72.96 \%$ to $83.3 \%)$ & \\
$\geq 40$ years (number, \%) (lower CL to upper CL) & $17(6.5 \%)(3.85 \%$ to 10.26\%) & \\
\hline
\end{tabular}

CL, confidence limits. 
Table 4 Factors associated with attendance of a prenatal education course

\begin{tabular}{|c|c|c|c|}
\hline & \multicolumn{2}{|c|}{ Attendance of prenatal education course } & \multirow[b]{2}{*}{ P value $\left(\chi^{2}\right)$} \\
\hline & Yes $(n=116)$ & No $(n=448)$ & \\
\hline \multicolumn{4}{|c|}{ Maternal age distribution, years } \\
\hline $30-39(n=403)$ & $85(21.2 \%)$ & $318(78.9 \%)$ & \\
\hline$\geq 40(n=31)$ & $7(22.6 \%)$ & $24(77.4 \%)$ & \\
\hline Shanghai $(n=448)$ & $91(20 \%)$ & $357(80 \%)$ & 0.796 \\
\hline Non-Shanghai $(n=116)$ & $25(22 \%)$ & $91(78 \%)$ & \\
\hline \multicolumn{4}{|l|}{ Education level (number, \%) } \\
\hline Under tertiary $(n=18)$ & $2(11 \%)$ & $16(89 \%)$ & 0.328 \\
\hline Under graduate $(n=450)$ & $90(20 \%)$ & $360(80 \%)$ & \\
\hline $1(n=469)$ & $103(22 \%)$ & $366(78 \%)$ & 0.071 \\
\hline $2(n=95)$ & $13(14 \%)$ & $82(86 \%)$ & \\
\hline \multicolumn{4}{|l|}{ Gravida (number, \%) } \\
\hline $1(n=415)$ & $91(22 \%)$ & $324(78 \%)$ & 0.297 \\
\hline $2(n=122)$ & $22(18 \%)$ & $100(82 \%)$ & \\
\hline$\geq 3(n=27)$ & $3(11 \%)$ & 24 (89\%) & \\
\hline
\end{tabular}

of caesarean section on maternal request is an important factor, particular in the high rates of caesarean section, including the rate of caesarean section on maternal request in China. ${ }^{4}$ In our current study of uncomplicated pregnancies and deliveries, the rate of planned caesarean section on maternal request was $46 \%$. Previous study suggested that a supportive birth environment can minimise maternal stress and anxiety during labour and birth and support physiological birth. ${ }^{14}$ Unfortunately, due to limited resources of many healthcare facilities, the birthing environment in China may not always be conducive to supporting natural births.

Individual delivery room and family member support in labour are not routine practice in most maternity hospitals in China. Conditions like these could result in a fear of childbirth and increased psychological stress to pregnant women. In addition, the long-term one child policy, which extended from 1979 to 2015 , may contribute to changing women and their families' philosophy around childbirth. If a woman can only have one child, she may not consider the risks of a caesarean section on future pregnancies to be relevant. ${ }^{15}$

Increasing maternal age is associated with an increased caesarean section rates and women with advanced maternal age have the highest caesarean section rate. ${ }^{16}$ Advanced maternal age is associated with a number of complications of pregnancy such as pre-eclampsia and gestational diabetes mellitus, ${ }^{17}$ obstetric-assisted delivery (including emergency caesarean section), ${ }^{18-20}$ and obstetrics blood loss during labour and birth. ${ }^{21}$ These adverse outcomes during labour and birth could result in a fear to pregnant women with advanced maternal age. In our current study, we found that the rate of caesarean section on maternal request was significantly associated with maternal age. We found that in women who requested the planned caesarean section, $85 \%$ of them were over 30 years. The OR of an increase in caesarean section on maternal request in pregnant women over 30 years was 2.42 (95\% CL 1.597 to 3.666$)$, compared with pregnant women under 30 years. We also found that pregnant women between 30 and 39 years had the highest rate of caesarean section on maternal request.

Prenatal education courses are a common component of western antenatal care for a long time, but are not offered in most maternity hospitals in China. The main purpose of a prenatal education course is to support pregnant women to prepare for labour and birth and included information on the labour and birth process, pain management, breast feeding and care of the newborn. $^{22}$ The prevalence of attendance of prenatal education course was $33 \%$ in Canada ${ }^{23}$ and $84 \%$ in nulliparous women in Australia. ${ }^{24}$ However, prenatal education courses for pregnant women are a relatively new to our hospital (under 5 years). The current percentage of attendance at our prenatal education course was $25 \%$ in our hospital and $20 \%$ in our study, which is significantly lower than rates in western countries.

Our study has found a significant reduction (35\%) in the number of caesarean section on maternal request in pregnant women who attended a prenatal education course. 
Our finding is supported by other study that suggested that prenatal education courses were associated with higher rates of vaginal delivery. ${ }^{23}$ In our study, maternal age, educational level, parity, gravida and residence status did not influence pregnant women attending a prenatal education course. Other studies have showed that prenatal education courses are more likely to be attended by nulliparous women and older pregnant women. ${ }^{24}$ This higher attendance was also observed in pregnant women with higher income and higher education level. ${ }^{22}{ }^{24}$ The difference in factors associating with the attendance of a prenatal education course between our current study and other studies could be because that our prenatal education courses have only been running for 5 years in our hospital and it has not been strongly recommended yet, by midwife or obstetrician. As the courses are relatively new, we hope that our results will encourage obstetricians and midwives to recommend prenatal education courses to pregnant women.

Interestingly, we found that women who resided in Shanghai had a higher rate of caesarean section on maternal request compared with women who did not reside in Shanghai. We do not know the exact reason for this difference. Women who resided in Shanghai were significantly older than women who did not reside in Shanghai by 1.2 years $(p=0.006)$, but there was no other significant difference between two groups. As we have mentioned, further research in a multicentre trial is needed to further understand the similarities and differences in pregnant women characteristics and preferences in different parts of China

\section{CONCLUSION}

In this study of low-risk pregnant women at a tertiary hospital in Shanghai, China, we found that maternal age, residence status and attendance of a prenatal education course affect the rate of caesarean section on maternal request. Attendance of a prenatal education course significantly reduced the rate of caesarean section on maternal request. Our findings suggest that part of China's strategy to reduce the overall caesarean rate should include prenatal education courses.

Acknowledgements Authors thank all women who participated in this questionnaire study. Authors also thank Dr Esther Woolston, an Obstetrician at Auckland City Hospital, The University of Auckland, New Zealand to review this manuscript.

Contributors All authors were involved in the drafting, editing and approval of the manuscript for publication. In addition to this, each author contributed to follow work. YG and YT: collected the data reported in this work. MT and YD: contributed to conception and design of this study. YD and QC: designed study and wrote the manuscript draft. QC: completed the revised manuscript.

Funding The authors have not declared a specific grant for this research from any funding agency in the public, commercial or not-for-profit sectors.

Competing interests None declared.

Patient consent for publication Not required.

Ethics approval This study was approved by the ethics board of The Hospital of Obstetrics and Gynaecology of Fudan University (Reference № 2017-04).

Provenance and peer review Not commissioned; externally peer reviewed.

Data sharing statement Data are available upon reasonable request.
Open access This is an open access article distributed in accordance with the Creative Commons Attribution Non Commercial (CC BY-NC 4.0) license, which permits others to distribute, remix, adapt, build upon this work non-commercially, and license their derivative works on different terms, provided the original work is properly cited, appropriate credit is given, any changes made indicated, and the use is non-commercial. See: http://creativecommons.org/licenses/by-nc/4.0/.

\section{REFERENCES}

1. Saeed KB, Greene RA, Corcoran P, et al. Incidence of surgical site infection following caesarean section: a systematic review and metaanalysis protocol. BMJ Open 2017;7:e013037.

2. Green B, Evans J, Subair S, et al. Maternal request for caesarean section: audit of a care pathway. J Obstet Gynaecol 2014;34:317-21.

3. Mazzoni A, Althabe F, Liu NH, et al. Women's preference for caesarean section: a systematic review and meta-analysis of observational studies. BJOG 2011;118:391-9.

4. Wang $X$, Hellerstein $S$, Hou $L$, et al. Caesarean deliveries in China. BMC Pregnancy Childbirth 2017;17:54.

5. Li HT, Luo S, Trasande L, et al. Geographic variations and temporal trends in cesarean delivery rates in China, 2008-2014. JAMA 2017:317:69-76.

6. Wiklund I, Andolf E, Lilja H, et al. Indications for cesarean section on maternal request--guidelines for counseling and treatment. Sex Reprod Healthc 2012;3:99-106.

7. Robson SJ, Tan WS, Adeyemi A, et al. Estimating the rate of cesarean section by maternal request: anonymous survey of obstetricians in Australia. Birth 2009;36:208-12.

8. Potter JE, Berquó E, Perpétuo IH, et al. Unwanted caesarean sections among public and private patients in Brazil: prospective study. BMJ 2001;323:1155-8.

9. MacDorman MF, Menacker F, Declercq E. Cesarean birth in the United States: epidemiology, trends, and outcomes. Clin Perinatol 2008;35:293-307.

10. Gao Y, Xue Q, Chen G, et al. An analysis of the indications for cesarean section in a teaching hospital in China. Eur J Obstet Gynecol Reprod Biol 2013;170:414-8.

11. Nieminen K, Stephansson O, Ryding EL. Women's fear of childbirth and preference for cesarean section--a cross-sectional study at various stages of pregnancy in Sweden. Acta Obstet Gynecol Scand 2009;88:807-13.

12. Kringeland T, Daltveit AK, Møller A. What characterizes women in Norway who wish to have a caesarean section? Scand J Public Health 2009;37:364-71.

13. Gao LL, Liu XJ, Fu BL, et al. Predictors of childbirth fear among pregnant chinese women: a cross-sectional questionnaire survey. Midwifery 2015;31:865-70.

14. Stark MA, Remynse M, Zwelling E. Importance of the birth environment to support physiologic birth. J Obstet Gynecol Neonatal Nurs 2016;45:285-94.

15. Sharpe AN, Waring GJ, Rees J, et al. Caesarean section at maternal request--the differing views of patients and healthcare professionals: a questionnaire based study. Eur J Obstet Gynecol Reprod Biol 2015;192:54-60.

16. Janoudi G, Kelly S, Yasseen A, et al. Factors associated with increased rates of caesarean section in women of advanced maternal age. J Obstet Gynaecol Can 2015;37:517-26.

17. Yogev Y, Melamed N, Bardin R, et al. Pregnancy outcome at extremely advanced maternal age. Am J Obstet Gynecol 2010;203:558.e1-558.e7.

18. Ludford I, Scheil W, Tucker G, et al. Pregnancy outcomes for nulliparous women of advanced maternal age in South Australia, 1998-2008. Aust N Z J Obstet Gynaecol 2012;52:235-41.

19. Timofeev J, Reddy UM, Huang CC, et al. Obstetric complications, neonatal morbidity, and indications for cesarean delivery by maternal age. Obstet Gynecol 2013;122:1184-95.

20. Herstad L, Klungsøyr K, Skjaerven R, et al. Maternal age and emergency operative deliveries at term: a population-based registry study among low-risk primiparous women. BJOG 2015;122:1642-51.

21. Herstad L, Klungsøyr K, Skjærven R, et al. Elective cesarean section or not? Maternal age and risk of adverse outcomes at term: a population-based registry study of low-risk primiparous women. BMC Pregnancy Childbirth 2016;16:23.

22. CBaK D. In what mothers say: the canadianmaternity care experience survey. Ottawa, Canada: Public Health Agency of Canada, 2009:47-50.

23. Stoll KH, Hall W. Childbirth education and obstetric interventions among low-risk canadian women: is there a connection? J Perinat Educ 2012;21:229-37. 
24. Lumley J, Brown S. Attenders and nonattenders at childbirth education classes in Australia: how do they and their births differ? 